ББК 67.401.13

\title{
САМООБРАЗОВАНИЕ МОЛОДЕЖИ МОСКВЫ И МОСКОВСКОЙ ОБЛАСТИ В УСЛОВИЯХ САМОИЗОЛЯЦИИ И ДИСТАНЦИОННОГО ОБУЧЕНИЯ: ОСОБЕННОСТИ И ТЕНДЕНЦИИ, ВЫЗВАННЫЕ ПАНДЕМИЕЙ COVID-19
}

\author{
(c) 2020 Щукина Татьяна Владимировна \\ доктор юридических наук, доцент, заведующая кафедрой прикладного права \\ Российский Технологический Университет - МИРЭА, Россия, Москва \\ (c) 2020 Борисова Анастасия Николаевна \\ магистр \\ Московский областной филиал РАНХИГС, Россия, Красногорск \\ (c) 2020 Попова Диана Вячеславовна \\ магистр \\ Московский областной филиал РАНХИГС, Россия, Красногорск
}

\begin{abstract}
Предметом настоящей статьи выступает анализ самообразования студентов в условиях обучения в дистанционном режиме в период пандемии COVID-19 путем исследования проявления желания у обучающихся самостоятельно получать новые знания путем чтения литературных произведений различных жанров. Методологию данной работы составили междисциплинарные методы, такие как конкретно-социологический, формально-логический, системно-структурный, сравнительноправовой. Кроме того, применялись общенаучные методы исследовательской деятельности: функциональный метод, метод обобщения, абстрагирования, методы формализации, наблюдения, сравнения. Для оценки перспектив самообразования студенческой молодежи, восприятия данного процесса студентами ведущих вузов и средних профессиональных учебных заведений Москвы и Московской области в июле 2020 года был проведен опрос на тему «Самообразование молодежи Москвы и Московской области в условиях самоизоляции и дистанционного обучения» Анастасией Борисовой и Дианой Поповой. В работе представлен структурный анализ ситуации с самообразованием студенческой молодежи в условиях самоизоляции, особенности чтения литературных и научных источников, организации собственного времени молодых людей на саморазвитие. В результате было установлено, что 1/3 студентов стала читать больше, находясь в режиме самоизоляции. Направление изучаемой литературы поменялось и отдавалось предпочтение классической литературной прозе и поэзии, а также высокая готовность студентов к самообразованию и развитию.
\end{abstract}

Ключевые слова: самообразование, COVID-19, литературные произведения, мотивация, инициатива, студенты, самоизоляция.

В современной науке термин «самообразование» рассматривается под различными углами зрения, существует множество позиций ученых относительно его содержания и структуры. Зачастую эти точки зрения являются взаимоисключающими друг друга. Одни авторы считают, «что самообразование невозможно в стенах учебного заведения» [1]. Другие подчеркивают - самообразование, прежде всего, приобретение знаний исключительно из дополнительных источников и сверх образовательной программы [2]. Третьи под «самообразованием» понимают образование, приобретаемое человеком в процессе самостоятельной работы, без прохождения систематического обучения в образовательном учреждении [3]. Одна позиция объединяет ученых в этом вопросе, которая связана с осознанием самообразования как взаимоувязанных процесса самоорганизации обучающегося лица и деятельности по пополнению имеющихся у него знаний. По мнению Коджаспировой Г. М., самообразование - это тщательно организованная, самостоятельная и систематическая деятельность, нацеленная на постижение окружающей среды и на достижение образовательных целей [4]. С авторской точки зрения, самообразование предполагает самостоятельное получение лицом по собственному желанию новых профессиональных, общекультурных знаний в различных сферах жизнедеятельности общества, которое 
позволяет осваивать дополнительные компетенции, формировать траекторию собственного развития и познания окружающей действительности как сверх образовательной программы, изучаемой в образовательной организации, так и вне образовательно-организационных форматов.

Наиболее распространенной формой самообразования является чтение и изучение литературных произведений. Последняя дефиниция наиболее точно описывает смысл предмета данного исследования, излагаемого авторами. Прежде отметим значение термина «самоизоляция». Это - комплекс ограничительных мер для населения, которые вводит правительство на определенный срок для борьбы с распространением опасного заболевания [5]. При введении подобного ограничительного режима осуществляется приостановление (ограничение, в том числе путем определения особенностей режима работы, численности работников) деятельности находящихся на соответствующей территории отдельных организаций независимо от организационно-правовой формы и формы собственности, а также индивидуальных предпринимателей; установление в случае необходимости особого порядка передвижения на соответствующей территории лиц и транспортных средств [6].

Распространение новой коронавирусной инфекции (COVID-19) стало глобальной пандемией и повлекло за собой негативные экономические последствия и применением вынужденных мер ограничения передвижения граждан. Одной из ключевых мер стала самоизоляция граждан в марте - июне 2020 года.

В связи с мировой пандемией COVID-19 и применением мероприятий самоизоляции в Российской Федерации у студентов появилось больше свободного времени, так как все формы обучения, включая текущую работу, промежуточный контроль в виде зачетов и экзаменов, стали проводиться в дистанционном формате. Подобный режим обучения исключил из общего количества времени, затрачиваемого на процесс образования у обучающихся лиц, время на поездки до места учебы и обратно. Кроме того, ограничение прогулок по паркам, скверам, посещений культурно-развлекательных мероприятий и т.п. сформировало большое количество свободного времени. Времени, которое студенты, заинтересованные в повышении уровня своих знаний, могли направить на свое самообразование. Именно, особенности распределения и использования студентами свободного времени в период самоизоляции анализируется авторами в данном исследовании.

Для оценки перспектив самообразования студенческой молодежи, восприятия данного процесса студентами ведущих вузов и средних профессиональных учебных заведений Москвы и Московской области в июле 2020 года был проведен опрос на тему «Самообразование молодежи Москвы и Московской области в условиях самоизоляции и дистанционного обучения» Анастасией Борисовой и Дианой Поповой (https://docs.google.com/forms/d/e/1FAIpQLSch Qy027E2nPHa2vkMlsKm8CQoL6YQTPaSWj7 -C_XH2EhttWg/viewform). Авторский коллектив постарался выяснить следующее: повлияла ли санитарно-эпидемиологическая ситуация в Российской Федерации в период введения режима самоизоляции на желание студентов и в целом молодежи от 16 до 30 лет в Москве и Московской области больше читать литературные источники и, собственно,- самообразовываться. Сначала проведения исследования у авторов было предположение о том, что в связи со сложившейся санитарно-эпидемиологической ситуацией в период с марта по июнь 2020 года, у студентов появилась тенденция обретать новые знания, совершенствоваться и корректировать сферу интересов. В этих целях авторами было проведено социологическое исследование, где студентам средних и высших учебных заведений предлагалось ответить на ряд вопросов.

Контингент респондентов составил 150 студентов в возрасте от 16 до 30 лет, получающих образование по различным формам и направлениям подготовки от среднего профессионального образования до подготовки кадров высшей квалификации (аспирантура) (рис. 1).

Большую часть респондентов составили лица в возрасте от 19 до 23 лет, обучающиеся в высших учебных заведениях (рис. 2).

Респондентам предлагалась ответить на следующие вопросы о том, как часто Вы читали до самоизоляции и в каком количестве литературу, каким жанрам отдавали предпочтение, читали ли научно исследовательские работы (далее НИР) и различные публикации в интернет сети (рис. 3).

Данные опроса показали, что 21,9\% из 150 опрашиваемых читали каждый день, 25,8\% читали несколько раз в неделю, 27,3\% - читали несколько раз в месяц (только по выходным дням), оставшиеся 25\% читали до самоизоляции 
Вопрос № 18 Укажите Ваше образование:

128 ответов

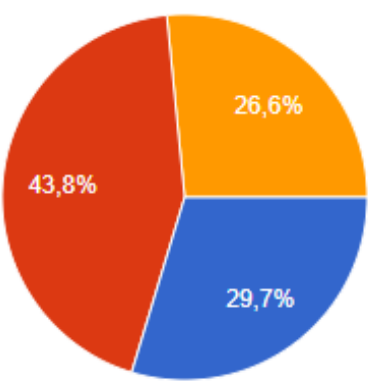

А) я учусь в колледже/ училище/ техникуме либо окончил учебу в перечисленных заведениях

Б) я учусь в бакалавриате/ специалитете или окончил учебу по данным программам

В) я учусь в магистратуре / аспирантуре/ординатуре либо окончил учебу по данным программам

Puc. 1. Формы обучения и направления подготовки респондентов

Вопрос № 17 Сколько Вам лет?

128 ответов

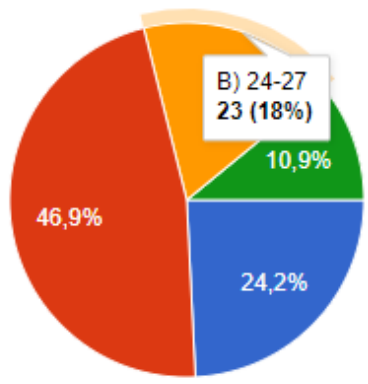

A) $16-18$

Б) $19-23$

B) $24-27$

д) $28-30$

Puc. 2. Возраст респондентов

Вопрос № 3 Книги какого жанра вы предпочитали до самоизоляции? (возможно несколько вариантов ответа)

128 ответов

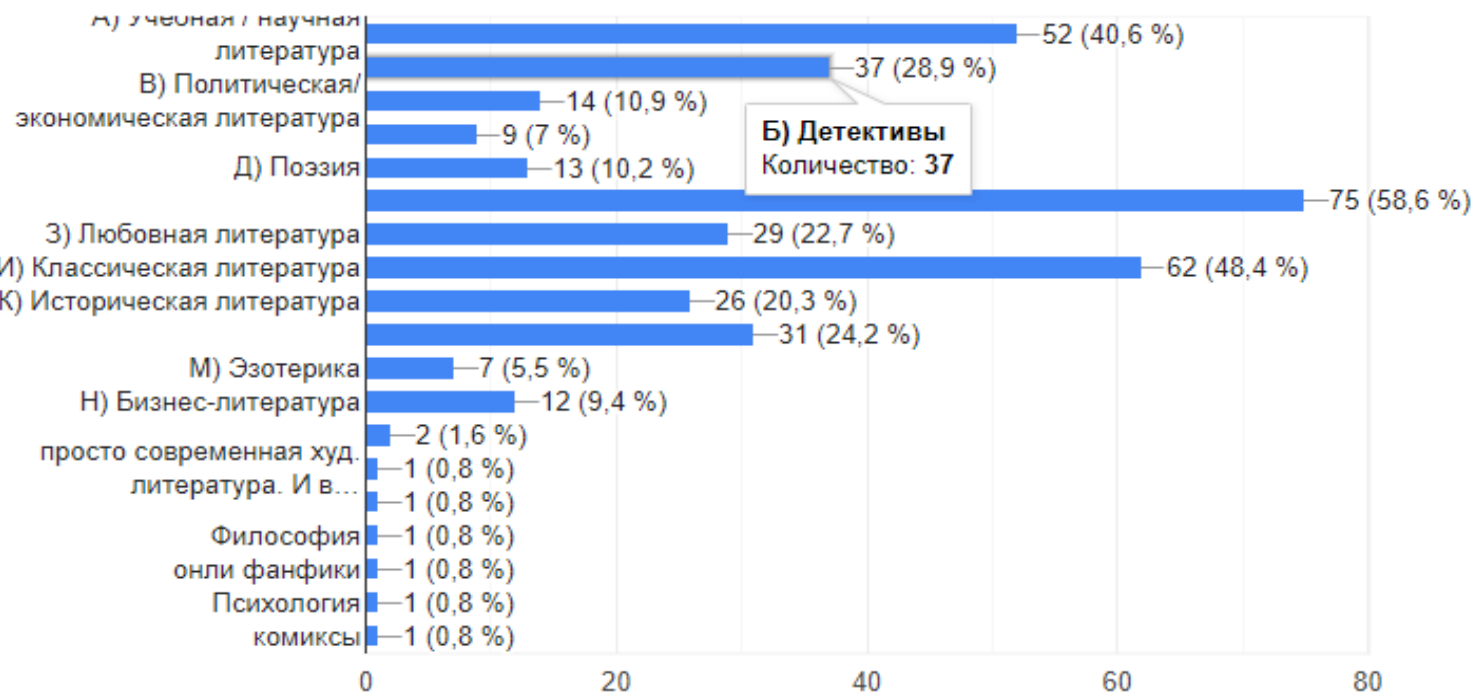

Puc. 3. Предпочтения в чтении литературы респондентами до самоизоляции 


\section{1-2 раза в год (рис. 4).}

По данным опроса 8,6\% студентов читало 3-4 книги в месяц и соответственно от 36 до 50 книг в год. $21,1 \%$ респондентов читали $2-3$ книги в месяц (от 25 до 35 книг в год). 1-2 книги в месяц (от 10 до 24 книг в год) читали 27,3\%, а оставшиеся $42,9 \%$ респондентов читало меньше 10 книг год (рис. 5).

На вопрос, читали ли вы научные публикации до самоизоляции, «да» ответили $64,8 \%$ респондентов (рис. 6).

На уточняющий вопрос: «Научные публикации какого жанра вы предпочитаете» - 67,8\% респондентов предпочли учебную/научную литературу, политические и экономические исследования $-29,9 \%$, на тему бизнеса и управления читают $26,4 \%$ учащихся (рис. 7 ).

Больше всего авторов опроса интересовал ответ вопрос, касающийся того, а стали ли читать больше респонденты, находясь в режиме самоизоляции. «Стал читать больше» - ответили 29,7\% респондентов, «читаю столько же»$57 \%$ и $13,3 \%$ респондентов стали читать меньше (рис. 8).

Респондентам также был предложен вопрос: «Как часто и в каком количестве Вы читаете, находясь в режиме самоизоляции?». «Читаю каждый день» ответили 35,2\% респондентов, «читаю несколько раз в неделю» - 29,7\% респондентов, $27,3 \%$ студентов читали пару раз за весь период самоизоляции (рис. 9).

При этом 14,1\% прочитывали одну книгу в неделю, 3-4 книги в месяц прочитывали 10,9\%, $14,1 \%$ - читали 2-3 книги в месяц, оставшиеся $12,5 \%$ респондентов вообще не читали. Проведя сравнительный анализ полученных данных со статистическими данными периода до самоизоляции, можно сделать вывод, что по каждому из пунктов показатели, несомненно, возросли (рис. 10).

Вопрос № 1 Как часто вы читали до самоизоляции?

128 ответов

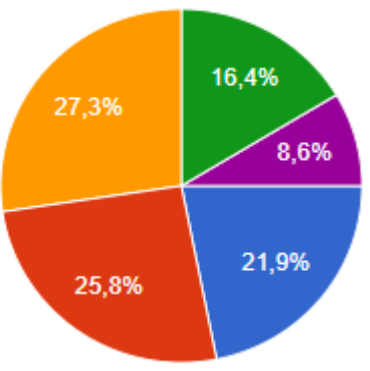

А) каждый день

Б) несколько раз в неделю

В) только на выходных/несколько раз

в месяц

Г) несколько раз в год (например,

только на каникулах)

Д) обычно нет желания читать

Puc. 4. Структура чтения литературы респондентами до самоизоляции

Вопрос № 2 Как много вы читали до самоизоляции?

128 ответов

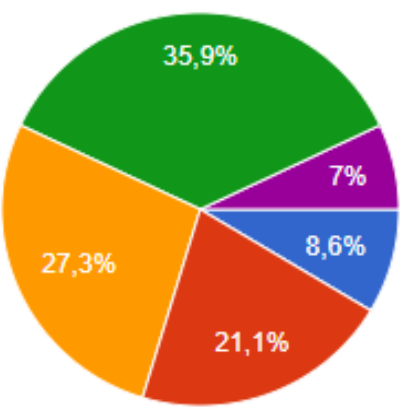

А) 3-4 книги в месяц, от 36 до 50 книг

в год

Б) 2-3 книги в месяц, от 25 до 35 книг в год

В) 1-2 книги в месяц, от 10 до 24 книг в год

Г) меньше 10 книг в год

Д) не читал

Puc. 5. Количество чтения литературных источников респондентами до самоизоляции 
Вопрос № 4 Читали ли вы научные публикации до самоизоляции?

128 ответов

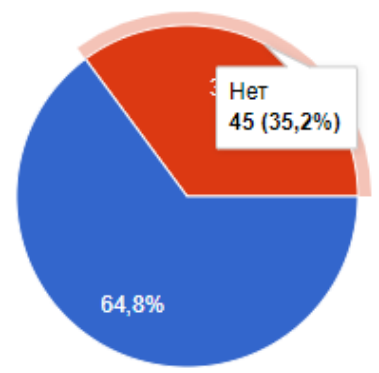

Да

Нет

Puc. 6. Количество респондентов, читавших научную литературу, до самоизоляции

Вопрос № 5 Научные публикации какого жанра Вы предпочитаете ?

87 ответов

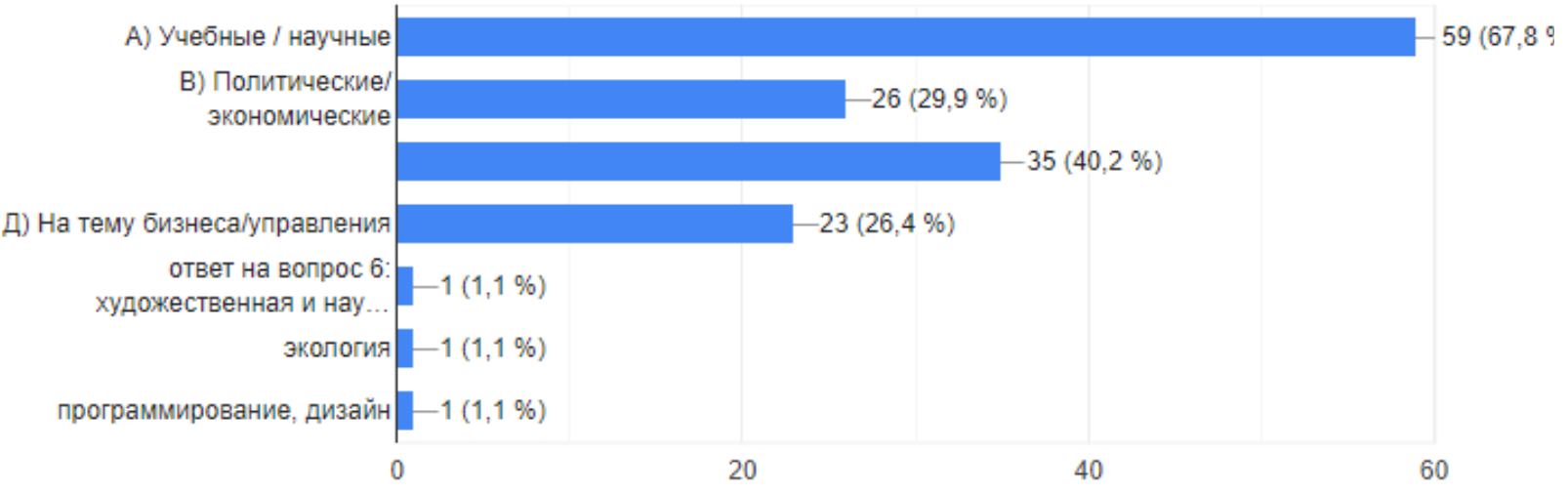

Puc. 7. Структура чтения научной литературы респондентами

Вопрос №9 Стали ли вы читать больше, находясь в режиме самоизоляции?

128 ответов

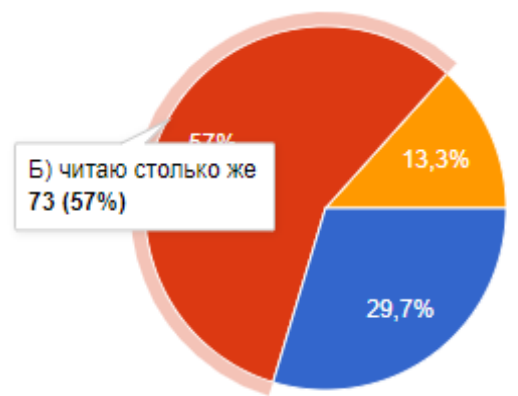

А) стал читать больше

Б) читаю столько же

В) стал читать меньше

Puc. 8. Структура чтения литературы респондентами в период самоизоляции 
опрос № 10 Как часто вы читаете, находясь в режиме самоизоляции?

28 ответов

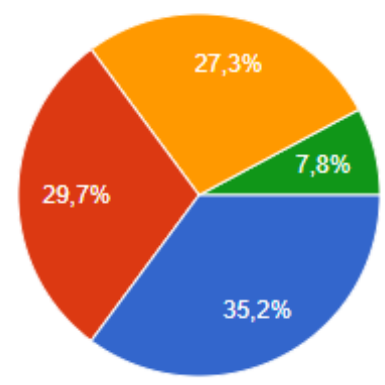

А) каждый день

Б) несколько раз в неделю

В) читал пару раз за весь период самоизоляции

Д) нет желания читать

Puc. 9. Структура чтения литературы респондентами во время самоизоляции

Вопрос №11 Как много вы читаете во время самоизоляции?

128 ответов

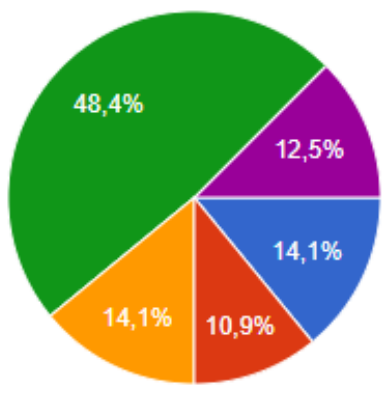

А) по крайне мере одну книгу в неделю

Б) 3-4 книги в месяц

В) 2-3 книги в месяц

Г) 1-2 книги в месяц

Д) не читал

Puc. 10. количество читаемой литературы респондентами во время самоизоляции

На вопрос: «Книги какого жанра вы читаете во время самоизоляции?» респонденты ответили следующим образом: 36,7\% молодежи предпочитает учебную/научную литературу, 47,7\% предпочитает фантастику/фетези/мистику, а классическую литературу читает $43,8 \%$ респондентов. Формулируя данный вопрос перед респондентами, авторы полагали, что студенты частично сменят свои предпочтение, уделяя больше времени на литературу медицинской направленности. Однако данная гипотеза потерпела неудачу и доказательства этого приведены на рисунке 11.

Далее, авторы предполагали также, что во время самоизоляции учащиеся станут больше читать интернет статьи. Однако, число студентов, читающих статьи этого типа, не только не увеличилось, но и наоборот, сократилось на $32,1 \%$. В связи с чем, авторы пришли к выводу - онлайн обучение психологически утомляло студентов, а «живая» книга служила неким антистрессовым фактором (рис.12).

В отношении НИР следует отметить, что и во время самоизоляции, и до нее самым популярным жанром остаются учебные/научные статьи (рис. 13).

В итоге авторами сделаны следующие выводы, что $1 / 3$ студентов стала читать больше, находясь в режиме самоизоляции. Направление изучаемой литературы поменялось и отдавалось предпочтение любовной, классической литературе и поэзии. Медицинская литература популярностью не пользовалась, несмотря на пандемию. Получается, что саморазвитие, самосовершенствование человека и самообразование находятся в неразрывной связи друг с другом. А стрессовые и нестабильные ситуации порождают мотивацию к процессам саморазвития, в частности для учащейся молодежи условия пандемии стали импульсом к усилению самообразования, к движению вперед, поиску смыслов и обновлению приоритетов. 
Вопрос № 12 Книги какого жанра вы читаете, находясь в режиме самоизоляции? (возможно несколько вариантов ответа)

128 ответов

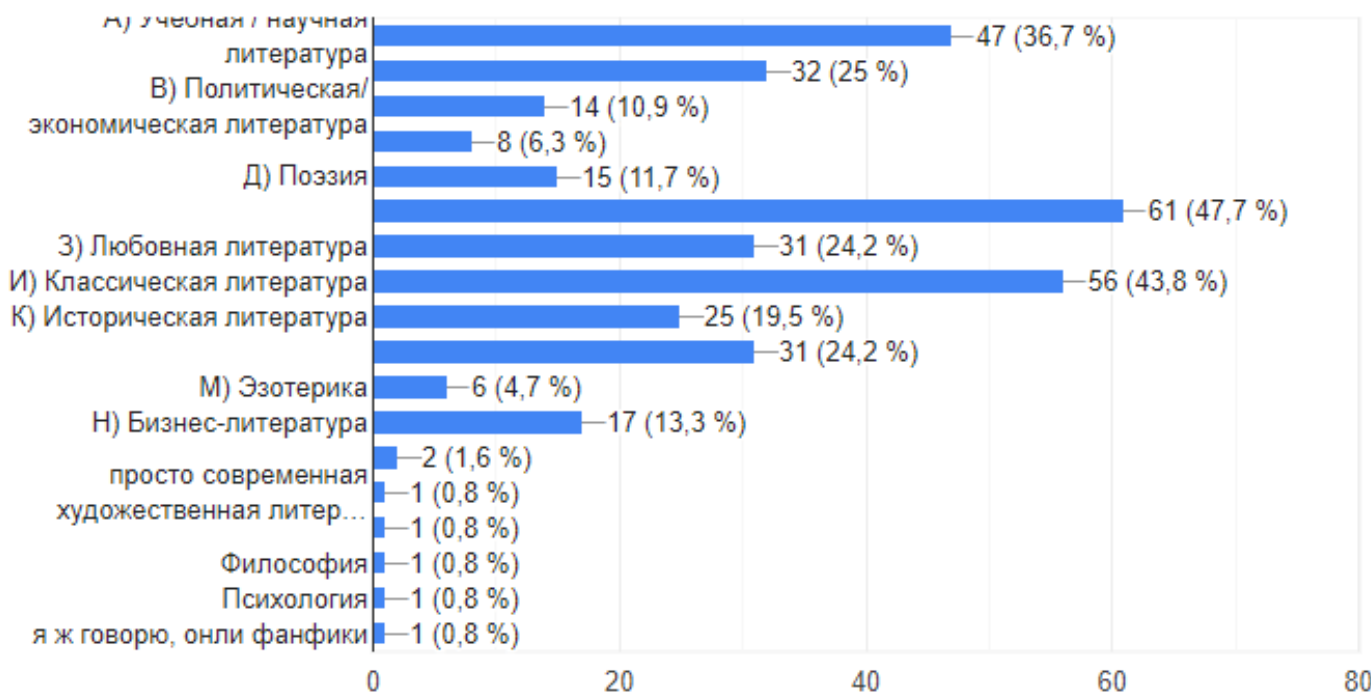

Puc. 11. Жанровая структура чтения литературы респондентами во время самоизоляции

Вопрос № 15 Читаете ли вы интернет-статьи во время самоизоляции?

128 ответов

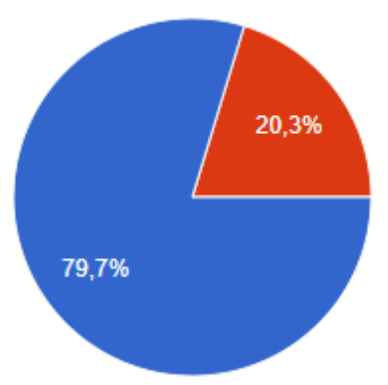

Да

- Нет

Puc. 12. Количество респондентов, читавших статьи в Интернете во время самоизоляции

Вопрос № 13 Читаете ли вы научные публикации, находясь в режиме самоизоляции?

128 ответов

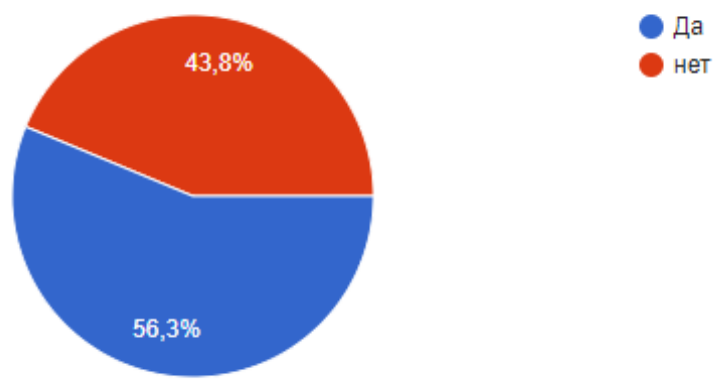

Puc. 13. Структура чтения научной литературы респондентами во время самоизоляции 


\section{Библиографический список}

1. Калинина А.И. Сущность понятия «самообразование» // Вестник Московского университета. Серия. Педагогическое образование. 2013. № 3. С. 102.

2. Там же. С. 102.

3. Боранбаева А.Р., Беркимбаев К. М., Арымбаева К. М. Понятие, содержание и элементы самообразования. Режим доступа. URL: https://cyberleninka.ru/article/n/ponyatie-soderzhanie-i-elementy-samoobrazovaniya

4. Коджаспирова Г. М. Культура профессионального самообразования педагога / под ред. Ю. М. Забродина. М.: Просвещение, 1994.

5. Что значит режим самоизоляции для всех с юридической точки зрения. Режим доступа. URL: https://ria. $\mathrm{ru} / 20200408 / 1569764617 . \mathrm{html}$

6. Об определении порядка продления действия мер по обеспечению санитарно-эпидемиологического благополучия населения в субъектах Российской Федерации в связи с распространением новой коронавирусной инфекции (COVID-19): Указ Президента РФ от 11 мая 2020 г. № 316 // Собр. законодательства Российской Федерации. 2020. № 20. Ст. 3157 